\title{
Influence of Plasmodium falciparum Parasitaemia on White Blood Cell among children (6-59 Months). A Case Study of Comprehensive Health Centre Bulumkutu, Maiduguri, Borno, State - Nigeria
}

\author{
Inuwa Yahaya*, Mohammed Isa Tada**, Musa Abubakar**** \\ *Department of Biological Sciences, Faculty of Science, University of Maiduguri, PMB 1069, Maiduguri, Nigeria. \\ *Department of Biological Sciences, Faculty of Science, Federal University of Kashere, PMB 0182, Gombe State, Nigeria. \\ ${ }^{* *}$ Department of Biological Sciences, Faculty of Science, University of Maiduguri, PMB 1069, \\ Maiduguri Nigeria. \\ *** Department of Basic Sciences, Mohamet Lawan College of Agriculture P.M.B. 1427 Maiduguri, Nigeria.
}

DOI: 10.29322/IJSRP.11.02.2021.p11037

http://dx.doi.org/10.29322/IJSRP.11.02.2021.p11037

\begin{abstract}
This study was conducted to assess the influence of Plasmodium falciparum parasitaemia on Platelate (children) (659), at Bulumkutu Comprehensive Health Centre Maiduguri, Borno State, between August to December, 2018. A total of 210 children were enrolled in the study which consisted of 88 (41.9\%) patients with positive $P$. falciparum malaria and $122(58.10 \%)$ negative malaria. Hematological parameters were analyzed using sysmex haematology auto-analyser (2011), while the Giemsa stained slides thick and thin blood films were prepared from the stock solution, and tested for Plasmodium falciparum malaria and count of malaria parasite density. A positive correlation was observed between the parasite density and white blood cell of (children tested positive) as index of leucocytosis ( $\mathrm{r} 2=0.831, \mathrm{P}=$ 0.001 ) and positive correlation was observed between parasite and white cells of males females subjects respectively, where $\left(\mathrm{r}^{2}=\right.$ $0.735, \mathrm{p}=0.001)$ for males and $(\mathrm{r} 2=0.710, \mathrm{p}=0.001)$ for females.
\end{abstract}

\section{INTRODUCTION}

$\mathrm{M}$ alaria is an acute and chronic parasitic disease caused by an obligate intracellular protozoan of the genus Plasmodium. (Eneanya, 1996). It is caused by the protozoan parasites of Plasmodium species and transmitted through the bites of infected female Anopheles mosquitos. The miseries these parasites inflict on humans remain a major health challenge and a problem worldwide (Oluwafemi, 2003). The genus Plasmodium has four species, causes malaria in man, namely Plasmodium vivax, Plasmodium malariae, Plasmodium ovale and Plasmodium falciparum (Ukagaet al., WHO, 2003 2000). Plasmodium falciparum is the most virulent species and accounts for over $90 \%$ of human malaria infection (Ekanamet al., 1990). Malaria is an endemic parasitic infection in more than 99 countries and it is one of the world major causes of death worldwide (Fortin et al., 2002). Haemalologic changes are the most common complications Malaria which plays a major role in the fatal complications. They include anaemia, cytoadherence of infected red blood cells, leucocyte changes, thrombocytopenia and coagulopathy (Parithran, 2007). Changes in leucocyte proliferation and function are seen with severe Plasmodium infection. Leucocyte proliferation associated with release of cytokines which are involve in cytoadherence, thrombocytopenia, disseminated intravascular coagulation hypoglacemia and lactic acidosis (Parithran, 2007).

The previous studies confirmed hematological abnormalities are considered a hallmark of malaria infection are common and are pronounced in Plasmodium falciparum malaria infection, probably due to higher levels of parasiteamia found in these children. The abnormalities previously reported include changes in parked cell volume, platelets, leucocyte, differential leucocyte counts and disseminated intravascular coagulation (DIC) (Reyburn et.al.,2007), (Wickramasignleet.al., 2000), (Richards et.al., (1998). (Bushawriet.al., (2002) (Chiwakataet.al., (2000), reported that there was no significance difference in white blood cells count between malaria infected and non-infected groups. Atypical Lymphocitosis, leucopenia and leukocytosis neutrophilia, eosinophilia and monocytosis have all been reported (Abro et al., 2008) leucopenia appears as a common finding in a patient with Plasmodium falciparum malaria when white blood cell counts may be as low as 1-2X109/ 1 (Erhabor et al., 2006). Changes in leucocyte proliferationsuch as leucopenia have been reported in severe Plasmodium falciparum (Abro et al., 2008).

\section{LITERATURE REVIEW}

\section{Leucocytes Changes in Plasmodium Infections}

Haemalologic changes which are the most common complications in Malaria play a major role in the fatal complications. They include anaemia, cytoadherence of infected red blood cells, leucocyte changes, thrombocytopenia and coagulopathy (Pavithran, 2007). Changes in leucocyte proliferation and function are seen with severe Plasmodium infection. Leucocyte proliferation is associated with release of cytokines which are involve in cytoadherence, thrombocytopenia, disseminated intravascular coagulation hypoglacemia and lactic acidosis (Pavithran, 2007). 
The white blood cells play a pivotal role in defense against Plasmodium infection (Staedke et.al., 2004). It is also identified as a strong determinant of anti-malaria drugs safety and efficacy (white and Olliaro (1996), (Plowe et.al., (2005) (Oyakhiroma et.al., (2007). Changes in white blood cells counts are response to parasite densities during follow up periods in treated children in Plasmodium falciparum infection but varies (Abro et.al., 2008) and as a result of either levels of acuteness of infection (Fanello et.al., 2006) parasitaemia (Pitmang et.al., 2005) or host immunity (Ladhani et.al., 2002). The total white blood cell counts within acute Plasmodium falciparum infection in children are usually within normal ranges in healthy individual, but there may be a slight decrease or upsurge (Leucocytosis) from the normal reference range.

In innate immunity, monocyte macrophages are the main immune effectors for controlling malaria blood stage infection via phagocytiv activity (Seghides et.al., 2003). Activation through pattern recognition receptors (PRRs) present on monocytes, dendritic cells and neutrophils indece release pro inflammatory cytokines and chemokines the development of acquired immunity (Kolli et.al., 2013). During acute infection monocytes produce high level of IL-IB,OL-112 and TNF- $\alpha$ (Fell and Smith, 1998), where as malaria pigment, hemozoin $(\mathrm{Hz})$, production by monocytes contributing to dendritic cell maturation (Jaramillo et.al., 2004). In humans, an impaired function on the maturation of monocytes and DCs due to malaria has been indicated by the reduced numbers of blood DCs (Pichyangkul et.al., 2004) inducing pregnan women (Diallo et.al., 2008).

Eosinophils may play a role in the protection against malaria (Plasmodium falciparum) by induction of parasite killing Walter, et al, 1987) but they may also contribute to pathology by release of granule proteins such as eosinoiphil catonic protein (EC) as eosinophil protein $\mathrm{x}$ leasinophil-derived neurotoxin (EPX) (Durack et al., 1981).

Patients suffering from malaria present with a number of hematological changes of which anaemia is a major complication especially in those infected with $P$. falciparum. (Weatheray et al., 1982). Other changes include easinophil concentration on neutrophils and lymphocyte, thrombocytes and neutrophilic leukocytosis (Pukrittayakarne et al., 1989). P. falciparum malaria also causes accelerated turnover of coagulation cascade. In severe disease, there is increased fibrinogen consumption, but in most cases plasma concentrations are either normal or elevated (Pukrittayakarnee et al., 1989).

\section{MATERIAL AND METHOD}

\section{STUDY AREA}

Maiduguri Lies on latitude $11^{\circ} 40^{\prime} \mathrm{N}$ and longitude $13^{0}$ 5 'E. The state occupies the greater part of the Chad basin and is in the North eastern part of Nigeria, the state share borders with the republic of Niger to the North, Chad to the North east and Cameroon to the East. Within Nigeria, the state shares boundaries with Adamawa state to the south, Gombe state to the west and Yobe state to the North West.

Maiduguri is the Capital of Borno State. It is located in the Sahel Savannah region of northeast Nigeria. The climate of Maiduguri is favorable, with a mean annual rainfall and temperature of about $650 \mathrm{~mm}$ and $32^{\circ} \mathrm{C}$ respectively. The month of March and April are the hottest periods of the year with temperatures ranging between $30^{\circ} \mathrm{C}$ and $40^{\circ} \mathrm{C}$. It is usually cold and dry during the harmattan, November to January being the coldest months. (Borno State Ministry of Information. 2015).

\section{Ethical Clearance}

Ethical permission was obtained from the Ethical Committee of the University of Maiduguri Teaching Hospital, to carried out the blood analysis using sysmexhaemotology autoanalyzer of Immunology laboratory and it was also be obtained from Primary health Care Department, Maiduguri Metropolitan Council. Subject and head of Umaru Shehu Ultra Modern Hospital Bulumkutu, Maiduguri, Borno State were educated on the collection of the blood samples and significance of the study.

\section{Inclusion Criteria}

All consecutively recruited children aged between 6-59 months visiting the pediatric outpatient department of the Bulumkutu Comprehensive Health Centre, Maiduguri, Borno State with history of febrile illness and whose parents and guidance consented to their inclusion in this study will be eligible to participate as subjects for this study.

\section{Exclusion Criteria}

All children less than 6 months and greater than 59 months and whose parent did not give inform consent were excluded from participating in this study.

\section{Preparation and Examination of Blood Films}

Blood samples were obtained from patients by trained laboratory staff on duty. Thick and thin blood films were made by spreading a drop of blood on a clean, grease-free, labelled slide and then allowed to dry. The dried blood films were then stained with $10 \%$ Giemsa stain solution and washed after 10 min using clean water. The stained films were allowed to dry and on addition of a drop of immersion oil, each slide was examined under $\times 100$ objective lens for malaria parasites. The examination was conducted according to Cheesbrough (1999), while the densities of positive slides were estimated by the methods described by (WHO, 2008)

\section{Thick Blood Film}

The drop of well mixed whole blood was placed on a clean grease - free slide. Using a glass spreader, it was spread to the size of a small coin. The thickness was made in such a way that the hands of a wrist watch can be seen through the film. It was allowed to air dry free from dust and flies and labeled with patient identity. (Cheesbough, 1999).

\section{Thin Blood Film}

A drop of blood was placed at the centre near one end of a clean grease free slide. A glass spreader was placed on the slide and drawn back to touch the drop of the blood. When the blood spreads to the edges of the spreader, the spreader was moved forward at an angle of $45^{\circ}$ without interruption to obtain the thin blood film. It was allowed air dry to free from dust and flies and labeled with patient identify.

\section{Determination of parasite density}


The thick film slide was stained for 30 to 45 minutes with $3 \%$ Giemsa for the assessment of parasite density. The samples were examined using objectives of a research microscope (x100) asexual parasites were counted alongside with 200 leukocytes. In an even that parasite count was < 10 parasites/200 leukocytes; count was continued per 500 leucocytes. The parasite density was expressed as the number of asexual parasites per $\mathrm{ml}$ of blood by assuming a mean normal leukocyte count of $8000 / \mu 1$ of blood Gilles and Warrell, 1993 and modified by (WHO, 2008). Parasitaemia $($ per $\mu \mathrm{l})=$ number of parasites $\mathrm{x} 8000 /$ number of leucocytes (200/500).

\section{Blood Analysis}

The collected samples was transferred to the laboratory for the estimation of blood parameters such as white blood cells packed cell volume, lymphocytes, monocytes, neutrophil, eosinophil, platelets and by using sysmex hematology Autoanalyser, (2011). The result will be recorded alongside findings of each subject's data.

\section{Statistical Analysis}

Data collected were subjected to descriptive statistic using the statistical package for social science SPSS version 20.0 (Armand and Jon peck, 2011) and analysis software statistics version 8.0 (Microsoft, 2013) measure of central tendencies (standard deviation percentages) were determined.

\section{RESULTS}

Results presented in table 1 showed the characteristics of the base line of enrollment in the study population. A total number of 210 children were enrolled for the study52 $(24.76 \%)$ were male tested negative, 64(30.48\%) tested positive and $36(17.14 \%)$ were female tested negative and 58(27.62\%) were female tested positive. Mean S.D to estimate variability in the data set was observed, consequently the age of the subject were highly disperse

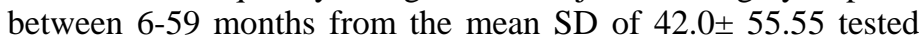
positive and $31.0 \pm 18.96$ tested negative

Table 1: Characteristics Baseline of Enrolment of the participant in Bulunkutu Health Centre, Maiduguri

\begin{tabular}{llll}
\hline Variables & Tested positive & $\begin{array}{l}\text { Tested } \\
\text { negative }\end{array}$ & Total \\
\hline $\begin{array}{l}\text { No enroll age } \\
\text { (month) }\end{array}$ & 88 & 122 & 210 \\
Mean & 42.00 & 31.00 & 73.00 \\
S.D & 55.55 & 18.96 & 74.51 \\
Range & $6-59$ & $6-59$ & $6-59$ \\
Gender & & & \\
Male & $52.0(24.76 \%)$ & $64.0(30.48 \%)$ & 116 \\
Female & $36.0(17.14 \%)$ & $58.0(27.62 \%)$ & 94 \\
\hline
\end{tabular}

The white blood cells were also found to be positively correlated with mean parasite densities among the malaria infected children 6-59 months $(\mathrm{r} 20.831, \mathrm{P}=0.001)$ and also among males subjects $\left(\mathrm{r}^{2}=0.735, \mathrm{P}=0.001\right)$ and female subjects $\left(\mathrm{r}^{2}=0.710, \mathrm{P}\right.$ $=0.001)$ as indicated in figure 1,2 and 3 respectively.

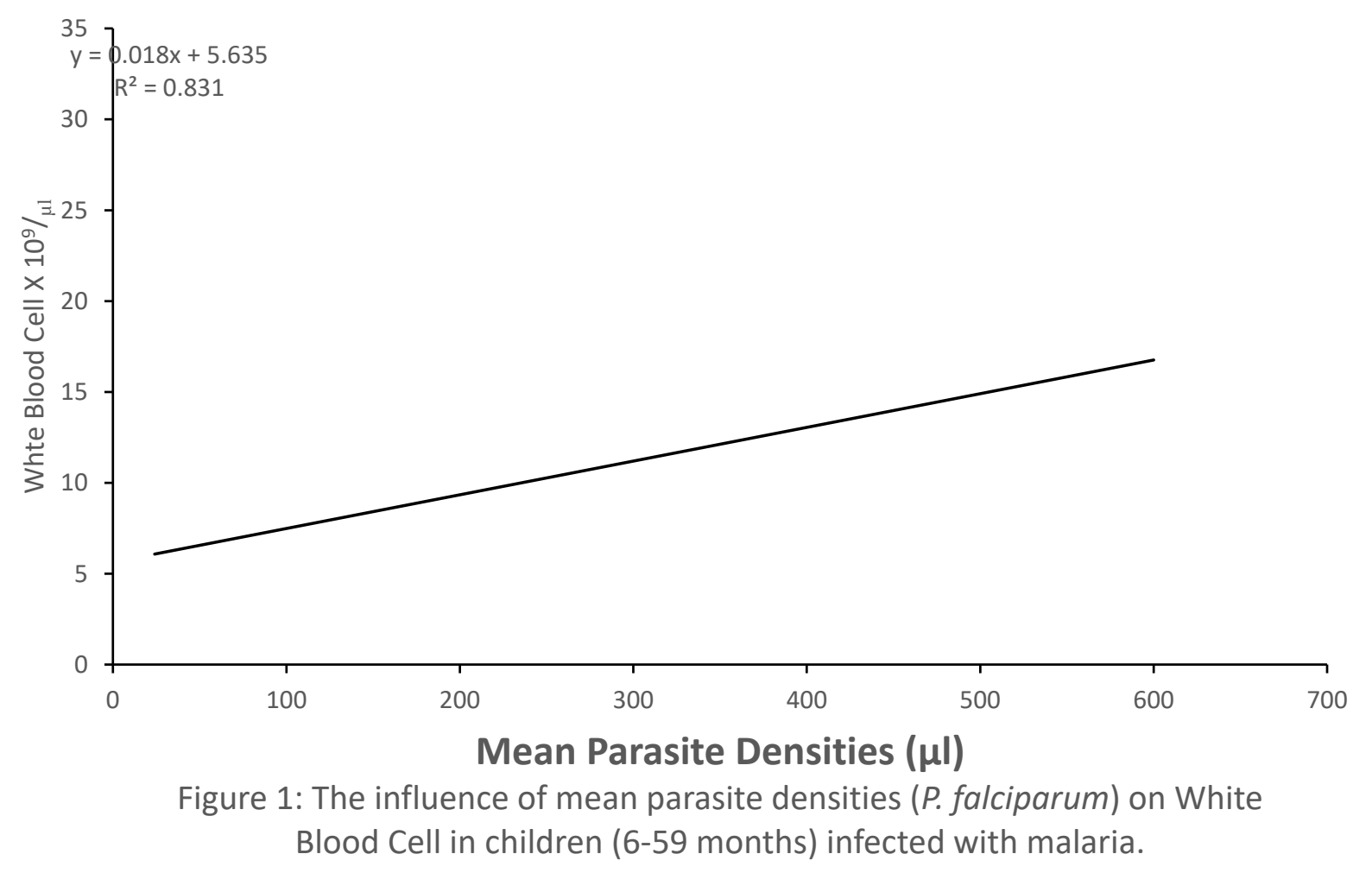




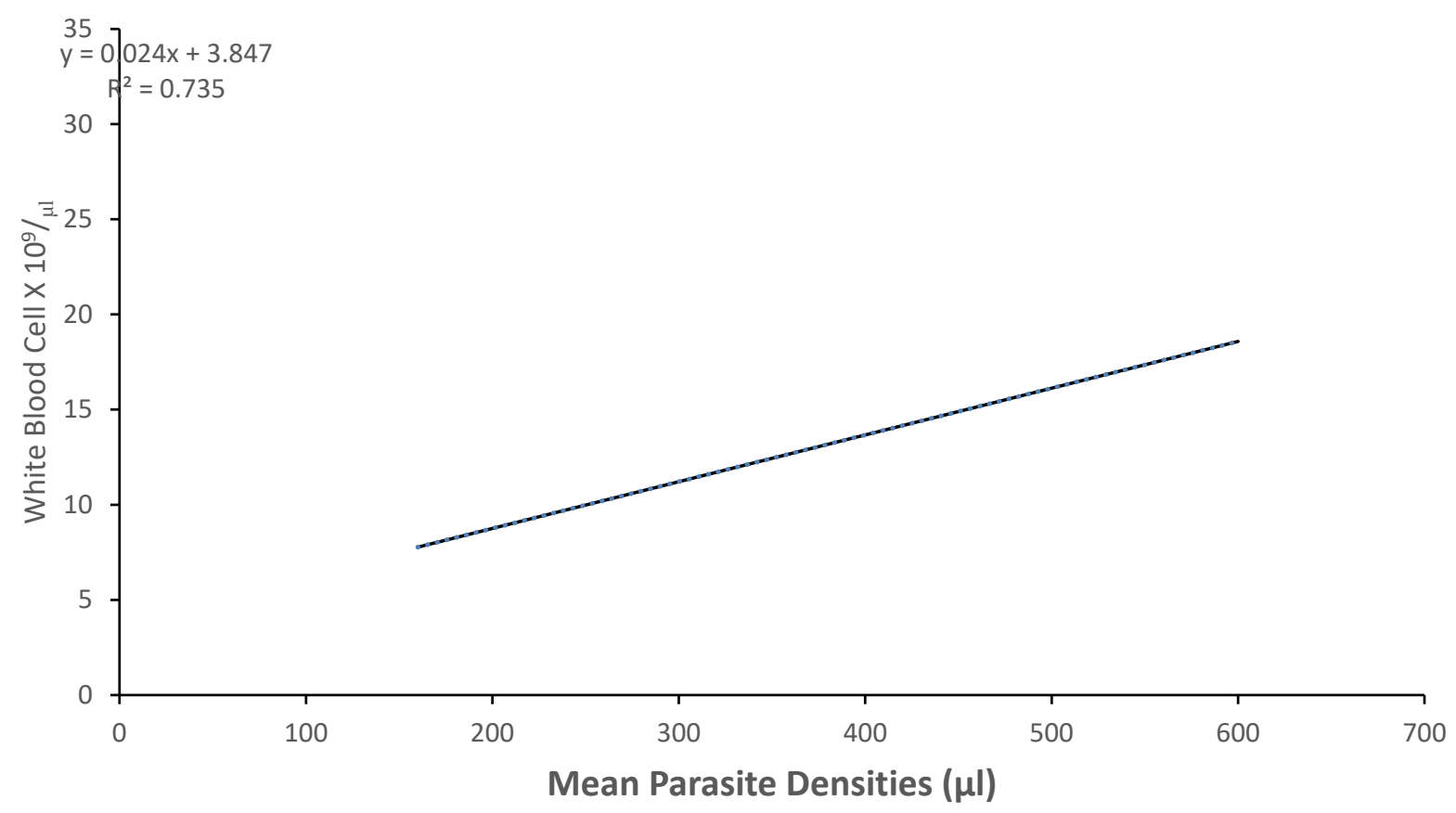

Figure 2: The influence of mean parasite densities ( $P$. falciparum) on White Blood Cell in male children (6-59 months) infected with malaria. 


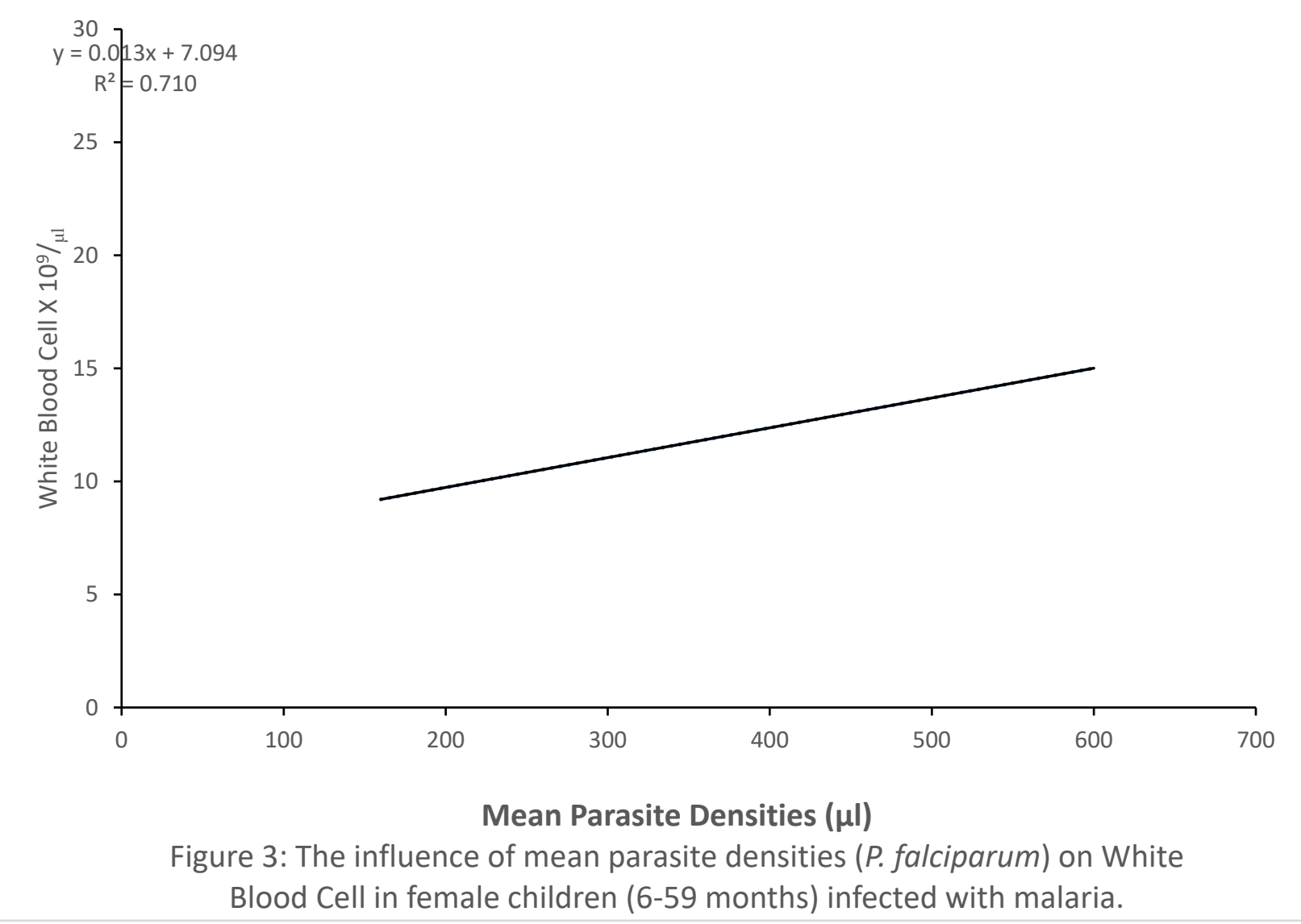

This publication is licensed under Creative Commons Attribution CC BY. 


\section{DISCUSSION}

The white blood cell plays a pivotal role in defence against Plasmodium falciparum infection Staedke et.al., (2004). The total white blood cell and differential leucocytes counts within acute Plasmodium falciprum infection in children are usually with normal ranges in healthy individual, but there may be a slight decrease from the normal reference range Rwagacondo, et.al, (2004).

Hematological changes are the most common complications that play a major role in those fatal complications. They include lysis of the red blood cell, leading to anaemia cytoadherence of infected red cells, leucocytes changes coagulopathy, particularly intravascular coagulated (Pavithran, 2007), others are lymphocytosis, leucopenia leucocytosis, neutrophilia and monocytosis have all been reported Abro et.al., (2008).

The study showed parasite densities influenced White Blood Cells in positive malaria in children (6-59months). A case study of Umaru Shehu Ultra Modern Hospital Bulumkutu, Maiduguri Borno. During this study it was observed that 210 (41.90\%) children aged between 6-59 months visited the pediatric outpatient department were positive for Plasmodium falciparum malaria. This finding is concurrent with previous reports from Nigeria by (FMOH, 2005) that obtained $40 \%$ annual prevalence rate found in Nigeria. This finding is also concurrent with previous report by Ojukwu, (2002) 50\% in North East, North Central, North West and South South regions of Nigeria respectively. But, this study contradicted other finding by Ojukwu, (2002) who in a similar research, in South Eastern part of Nigeria report 17\% prevalence rate.

There was a relatively higher prevalence of infection 52 (59.09\%) among males than females $36(40.91 \%)$ of female subject ( $>0.05 \%)$. However reports indicated higher prevalence in males than females (WHO, 2005; WHO, 2006) with no evidence on higher prevalence to gender susceptibility to malaria infection is not influenced by gender Giles and warell, (1993). The higher prevalence rate among male could just be by chance.

The mechanism of anaemia in parasitized patient is either due to the haemolysis of parasitized red cells, exacerbated removal of parasitized red blood cells bone marrow suppression and decreased enythroprotein level Pavithran, (2007).

The presence study indicated that there was a correlation between parasite densities and pcv among children aged 6-59 months with $\left.\mathrm{r}^{2}=0.508, \mathrm{P}=0.005\right)$ and as well as among males $\left(\mathrm{r}^{2}\right.$ $=0.680, \mathrm{P}=0.05)$ and females $\left(\mathrm{r}^{2}=0.537, \mathrm{P}=0.005\right)$ infected subjects as shown in fig. 1, 2 and 3 respectively. This means that as parasite density increases, pcv decreased. This agrees with an earlier investigation by Erhabor et.al., (2006) that Plasmodium falciparum parasitaemia is one of the commonest causes of anaemia and correlates with the severity of the infection. Furthermore, Kokori et.al., (2013) also reported that anaemia has correlated directly with Plasmodium falciparum parasitamia with $\mathrm{r}^{2}=(0.9841, \mathrm{P}=0.001)$.

\section{REFERENCES}

[1] Abro, A.H., Ustadi, A.M., Younis, N.J., Abdou, A.S., Hamed, D.A., \&Saleh, A.A., (2008). Malaria and haematological changes Pakistani Journal of Medical Sciences 24 (2): 27-287-291.

[2] Bashawri L.A, Mandil A.A, Bashnassy A.A Ahamed MA, (2002). Malaria: Hematological aspect Ann sandi med 2002; 22: 372-376.

[3] Cheesbrough, M, (1999). District Laboratory practice in tropical countries. Cambridge University Press. Volume 1:244-251.

[4] Chiwakata C.B, Hammer C.J, Dietrich M (2000) High level of inducible nitric oxide synhassmrna are associated with increased monocytes counts in blood and have a beneficial role in Plasmodium falciparum malaria infect Immun. 200; 68: 394 -0399. Doi: 10. 1128/1A1.68.1.394 - 399. 2000.

[5] Diallo M, Alderbert D, Moreau J.C., (2008). "Decreases of lymphoid dendrifits cells in blood from malaria infected pregnant women Int. J parasitol 2008; 28:1557-65.

[6] Durack D.T., Ackerman S.J, Loegering D.A., Gleich G.J., Purification Proc Natl Acad Sci of humaneosinophil-derived neurotoxin. USA 1981;78:51659. (PMC Free article) (PubMed).

[7] Ekanam, G.N., (1990). Pathology of malaria in West Africa.BlitMedical Journal, 1, 7 15-718.

[8] Enaeanya, C.F., (1996). Seasonal variation in malaria episodes among residents in Udi, a semi urban community in south east Nigeria. The Nigeria journal of parasitology. 19:39-43.

[9] Erhabour O., Babatude S. and Uko K.E (2006) some hematological parameters in plasmodia parasitized individual in Nigeria. Nigerian journal of medicine bold 52-55.

[10] Fanello, CL., Karema, C, van Doren, W, Rwagacondo C.E., \& D’Alessandro", U, (2006). Tolerability of Amodiaquine and sulphadoxinepyrimethamine, alone or uncomplicated Plasmodium falciparum malaria in Rwanda adults" Tropical and medicine and international Health. 11:589-596,

[11] Fell A.H., Smith., (1998). Immunity to Asexual Blood Stages of Plasmodium: is Resistance to Acute Malaria adaptive or Innate? Parasitol Today 1998; 14 : 364-9.

[12] Fortin, A, Stevenson, M.M., Gros, p. (2002) Susceptibility to malaria as a complex trait: big pressure from a tinycreature.Human Molecular Genetics, 11(20). 2469-2478

[13] Jaramillo M, Plante I, Ouellet N., (2004). Hemozoin-Inducible Preinfalmmatory Events in vivo: Potential Role in Malaria Infection. J Immunol 2004; 172:3101-10.

[14] Kolli D, Velayutham T.S., Casola A, (2013). "Host-Viral interactions: role of pattern I recognition receptors (PRRs) in human pneumo virus infections. Patogens 2013;2:2.

[15] Ladhani, S. Btett, L. Andrew, O. Cole, K.K., Charles, R, Newton .J.C, (2002) "changes in white blood c0.ells and platelets in children with falciparum malaria Relationship to disease outcome" British Journal of Hematology. Volume 119:3 pp 839-847,

[16] Oluwafemi, 0, Oguntibeju (2003). Parasitic Infestation and Anaemia: The Prevalence in a Rural Hospital Setting Journal, Indian Academy of Clinical Medicine, 4(3)

[17] Oyakhirome, S, Potschke, M, Schwarz, N.G., DOnemann, J, Laengin, M, Salazar, C.O, Lell B, Kun J.F., Kremsner, P.G., \& Grobusch, M.P., (2007) "Artesunate-Amodiaquine combination therapy for Plasmodium falciparum malaria in young Gabonese children" malaria Journal, 6:29-33,

[18] Pavithran, K, (2007). Haematological changes in Malaria. Clinical pharmacology 1:1-3.

[19] Pichyangkul S, Yongvanitchit K, Kumarb U, (2004). Malaria blood stage parasites activate Human Plasmacytoid Dendritic Cells and Munrine Dendiritic Cells through a toll-like recentor 9-dependent paltway. J immunol 2004; 172:4926-33.

[20] Plowe, C.V., Doumbo, O.K., Djimde A, Kayetao, K, Dourte, Y, Doumbo, S.N., COUlibaly, D, Thera, M, Wellems T.E., \& Diallo, D.A., (2001)"Chloroquine treatment of uncomplicated Plasmodium Falciparum malaria in mali: Parasitologic resistance versus therapeutic efficacy" American Journal of Tropical medicine and Hygiene 64: 242-246.

[21] Pukrittayakarnee. S, White, N.J., Clemens,R, (1989) "Activation of coagulation cascade in falciparum malaria. Trans. R. Soc. Trop. Med Hyg.;83 : 762-66.

[22] Reyburn H, Mbakilwa H, Mwangi R, Mwerinde O, Olomi R, Drakeley C, Whitty C.J (2007). Rapid diagnostic tests compared with malaria microslopy

This publication is licensed under Creative Commons Attribution CC BY.

http://dx.doi.org/10.29322/IJSRP.11.02.2021.p11037

WWW.ijsrp.org 
for guiding outpatient treatment of febrile illness in Tanzania randomized trial BMJ. 2007; 334: 403.Doi 10.1136/bmj. 39073. 496829. AE.

[23] Richard M.W, Behrens R.H, Doherty J.F (1998) Hematological change in acute, imported plasmodium falciparum malaria.AM.J. Trop med Hyg.1998; 59:859.

[24] Serghides L; Smith T.G., Patel S.N., Kain K.C., (2003).” CD36 and Malaria: Friends or foes? Trends Parasitol 2003; 50:143-5.

[25] Staedke, S.G., Mpimbaza A, Kamya, M.R., Nzarubara .B.K., (2004) " Dorsey, G. and Rosenthal, P.J. Combination treatments for uncomplicated falciparum malaria in Kampala Uganda randomized clinical trial" lancet. 364:1950-1957.

[26] Waters L.S, Taverne J, Tai P-C, Spry CFJ, (1987). “Target Gat, Playfair JHL Killing of Plasmodium falciparum by eosinophil secretory products. Infect Immum 1987;55:877-81 (PMC Free article) (PubMed).

[27] White, N, \& Oliaro P, (1996) "Strategies for the prevention of antimalarial drug resistance, rational for combination therapy for malaria'. Parasitology today. 12 (10); $399-401,1996$.

[28] Wickramasinghe SN, Abdalla SH. Bailliere'sClinHematol.Vol. 13.Harcourt Pub Ltd; 2000.Blood and bone marrow changes in malaria; pp. 277-299. [PubMed]

[29] World Health Organization, (2003). "Assessment and Monitoring of Antimalarial Drug Efficacy for the Treatment of Uncomplicated falciparum Malaria" Geneva, Switzerland WHO; 2003. Technical document WHO/RMB/HTM/2003.50,2003

\section{AUTHORS}

First Author- Inuwa Yahaya, B.Sc Zoology, M.Sc Applied Entomology and Parasitology, Department of Biological Sciences, Faculty of Science, University of Maiduguri, PMB 1069, Maiduguri, Nigeria, Federal University of Kashere, Gombe State, Nigeria.

Ibninuways1@gmail.com

Second Author- Mohammed Isa Tada, B.ED Biology Edu. M.Sc Arid Zone Ecology, Faculty of Science, University of Maiduguri, Borno State Nigeria

Mohammedisatada@gmail.com

Third Author-Musa Abubakar, B.Sc Zoology, M.Sc Envt. Mgt. Mohamet Lawan College of Agriculture Maiduguri, Borno state Nigeria.

abbakmusa@gmail.com

Correspondence Author- Musa Abubakar, Mohamet Lawan College of Agriculture Maiduguri, Borno state Nigeria. abbakmusa@gmail.com. +2348033713582 